\title{
SÍNDROME DE GUILLAIN-BARRÉ EM PACIENTE PEDIÁTRICO: RELATO DE CASO E REVISÃO DA LITERATURA
}

\section{GUILLAIN-BARRE SYNDROME IN PEDIATRICS PATIENTS: CASE REPORT AND LITERATURE REVIEW}

Laura Schwartz Maranhoํ, Guilherme Weiss Ribas ${ }^{1}$, Marcia Bandeira $^{2}$

\section{RESUMO}

Os autores descrevem o relato de uma paciente acometida pela síndrome de Guillain-Barré. Após a descrição, é realizada uma revisão da literatura dando ênfase nos principais aspectos diferenciais da forma adulta e pediátrica. Aspectos semiológicos, epidemiológicos, tratamento e prognóstico também são abordados no artigo.

Descritores: síndrome de Guillain-Barré; paralisia flácida; paralisia ascendente; paciente pediátrico.

\section{ABSTRACT}

Guillain-Barré syndrome is an acute desmyelinating peripheral neuropathy and is the most common cause of flaccid paralysis. It is characterized by progressive muscle weakness, ascending, bilateral and symmetrical. The objective of this study is to report the case of a patient, 12 years old, female, diagnosed with acute motor axonal neuropathy and electrophysiological changes.

Keywords: Guillain-Barré syndrome; flaccid paralysis; ascending paralysis; pediatric patient. 


\section{INTRODUÇÃO}

A síndrome de Guillain-Barré (SGB) é uma neuropatia periférica desmielinizante aguda e é a causa mais comum de paralisia flácida. ${ }^{1} \mathrm{~A}$ incidência pode variar conforme região e sexo, mas não tem relação com sazonalidade. Em países ocidentais varia de 0,89 a 1,89 por 100.000 pessoas (média de 1,11) e em crianças de 0,5 a 1,5 por 100.000 pessoas. Há discreta predominância no sexo masculino. Há também aumento de $20 \%$ a cada 10 anos após a primeira década de vida.1-3

O quadro clínico é formado por fraqueza muscular progressiva, ascendente, bilateral e simétrica das extremidades, que pode perdurar por 12 horas a 28 dia, e associado à arreflexia ou hiporreflexia e sintomas autonômicos, como hipotensão ortostática, hipertensão arterial transitória, íleo paralítico, disfunção vesical e sudorese.1,4 Em crianças, esse quadro é semelhante, porém a fraqueza muscular proximal é menos frequente e há mais envolvimento de pares cranianos, parestesia distal e dor neuropática (causada por lesão ou disfunção do sistema nervoso, como resultado da ativação anormal da via nociceptiva). 4,5

A maior parte dos casos é precedida por infecções do trato respiratório superior ou diarreia. Os principais agentes associados são Campylobacter jejuni (até $30 \%$ dos casos) e citomegalovírus (em até 10\% dos casos). ${ }^{1-8}$

As duas principais formas de apresentação são a polineuropatia aguda inflamatória desmielinizante (AIDP) seguida da neuropatia axonal aguda motora (AMAN). Há também a síndrome de Miller-Fischer (SMF) e a neuropatia axonal aguda sensório e motora (AMSAN). A AIDP é a mais comum (85-90\%) e corresponde ao quadro clínico citado acima. A AMAN, segunda mais comum (10-20\%), não é necessariamente grave e está mais ligada a infecção prévia por Campylobacter jejuni. ${ }^{1}$

O diagnóstico é clínico, mas os principais exames complementares solicitados são eletroneuromiografia (ENMG) e análise do líquor. No primeiro há alterações específicas para cada forma clínica e no líquor o principal achado é a dissociação albuminocitológica (aumento de proteínas com contagem de leucócitos normal).1,9 No exame neurológico observa-se debilidade simétrica dos membros inferiores com reflexos osteotendinosos ausentes ou diminuídos e dor neuropática. ${ }^{1}$ A escala Hughes (tabela 1) é usada para avaliar o comprometimento motor. ${ }^{1}$

O diagnóstico diferencial é realizado com todas as causas de paralisia flácida, principalmente meningoencefalite, poliomielite, botulismo, miastenia grave e miosite aguda infecciosa. ${ }^{1}$

O tratamento é feito com imunoglobulina intravenosa (IgIV) ou plasmaferese, ambas têm a mesma eficácia.1,10 A dose preconizada de IgIV é de $2 \mathrm{~g} / \mathrm{kg}$ dividida em cinco doses, uma vez ao dia. Já da plasmaferese, o recomendado é realizar cinco sessões em um período de duas semanas, totalizando a troca de cinco volumes de plasma. Deve-se também ofertar todo o suporte ventilatório e controle da dor que for necessário. ${ }^{1}$

Tabela 1. Escala Hughes

\begin{tabular}{ll}
\hline 0 & Totalmente saudável \\
\hline 1 & $\begin{array}{l}\text { Mínimos sinais e sintomas, apto a } \\
\text { andar. }\end{array}$ \\
\hline 2 & $\begin{array}{l}\text { Apto a andar mais que cinco minutos } \\
\text { sem assistência, mas incapaz de } \\
\text { correr. }\end{array}$ \\
\hline 3 & $\begin{array}{l}\text { Apto a caminhar mais que cinco } \\
\text { minutos com assistência. }\end{array}$ \\
\hline 5 & Acamado ou em cadeira de rodas. \\
\hline 6 & Requer assistência ventilatória em pelo \\
\hline
\end{tabular}

Fonte: João PRD. Síndrome de Guillain-Barré. PROTIPED, 2014.

O prognóstico em crianças é favorável, mas 20\% dos pacientes permanecem severamente incapacitados e $5 \%$ morrem de complicações como sepse, embolia pulmonar e parada cardíaca.1,4 Geralmente os pacientes que necessitaram de ventilação pulmonar mecânica (VPM) ou que apresentaram taquicardia e hipertensão, tem um pior prognóstico e requerem um tempo maior para alcançar a recuperação total.

Relatamos o caso de uma paciente, sexo feminino, 12 anos, com diagnóstico de neuropatia aguda motora com respectivas alterações eletrofisiológicas.

\section{RELATO DE CASO}

Feminino, 12 anos, deu entrada no pronto atendimento do Hospital Pequeno Príncipe, com quadro de paralisia e intensa dor nos membros inferiores. Há 21 dias, relatou início de dor nos membros inferiores que evoluiu com progressão ascendente, sensibilidade preservada e força muscular grau 5. Negava febre, cefaleia, náuseas, vômitos e diarreia. A dor impossibilitava a flexão dos joelhos, mas mantinha deambulação sem auxílio (grau 2 na escala Hughes). Na data do internamento, a dor já impossibilitava a deambulação sem auxílio (grau 4 na escala Hughes), mas no exame neurológico dos membros inferiores apresentava força muscular grau 0 , sensibilidade preservada e reflexos osteotendinosos (ROT) normais, já nos membros superiores apresentava força muscular grau 5, sensibilidade e ROT sem alterações. Um dado relevante é que a garota estava vivenciando o 
divórcio dos pais, e não aceitava o fato. Durante o internamento, manteve o quadro de paralisia e parestesia dos membros inferiores, sem progressão da doença. Após a eletroneuromiografia, que evidenciou padrão eletrofisiológico compatível com polineuropatia motora hiperaguda como observado na variante motora (AMAN) da SGB, foi solicitado o exame de líquor para confirmação do diagnóstico. O líquor veio com dosagem normal de proteínas totais e contagem normal de leucócitos. Mas, em vista do quadro clínico, da não melhora com os medicamentos para dor realizados durante o internamento e do resultado da ENMG, optou-se por iniciar a IgIV $2 \mathrm{~g} / \mathrm{kg}$ dividida em cinco doses, uma vez ao dia, por cinco dias. Após a administração da IgIV, a paciente teve melhora significativa da dor e conseguia deambular novamente sem auxílio (grau 2 na escala Hughes), no exame físico apresentava força muscular grau 5, sensibilidade preservada e ROT normais em membros superiores e inferiores. Recebeu alta hospitalar após 10 dias de internamento. Após um mês, retornou para consulta de controle e nesta data já havia retomado as atividades normais apresentando-se com grau 0 na escala Hughes. Além disso, não necessitava de medicação para dor.

\section{DISCUSSÃO}

O diagnóstico da SGB é feito por exclusão e depende de dois exames principais, a ENMG e avaliação do líquor. Neste último é importante se ter o valor de leucócitos e a contagem das frações de proteínas. 0 primeiro deve estar normal e o segundo deve apresentarse com um aumento do valor da albumina. Já na ENMG pode-se encontrar diferentes padrões de lesão neuronal, sendo os principais o desmielinizante e o axonal. No início do quadro clínico da paciente relatada, uma das hipóteses diagnósticas foi doença de origem psicossomática, uma vez que a paciente se encontrava deprimida com a separação dos pais. Descartada esta hipótese, a ENMG trouxe o diagnóstico da SGB na forma clínica, sendo então solicitado o exame de líquor para complementar a investigação e confirmar o diagnóstico. Neste caso relatado, o líquor não apresentou uma dissociação proteinocitológica, porém como não foi realizada a contagem das frações de proteínas, não se pode afirmar que não ocorreu a dissociação albuminocitológica.

A literatura mostra forte associação com infecção de via aérea superior ou gastrointestinal prévia. Porém a paciente relatada negou quadro infeccioso prévio ao início dos sintomas. Além disso, foi encontrado leve predominância no sexo masculino, sendo que a idade média de início dos sintomas é 9,02 + 5,17 anos. Outra característica encontrada na literatura que diferencia a SGB de crianças e adultos é que quanto menor for a idade do paciente maior é o envolvimento dos pares cranianos, parestesia distal e dor neuropática. A paciente em questão apresenta-se dentro da faixa etária esperada para o início dos sintomas e apresentou parestesia e dor com características neuropáticas, dois dos sintomas mais comuns em crianças.
$\mathrm{Na}$ evolução da doença, alguns pacientes necessitam de intubação orotraqueal e ventilação pulmonar mecânica, decorrente da insuficiência respiratória secundária a paralisia dos músculos respiratórios. A paciente relatada, não evoluiu desta forma e não necessitou de procedimentos mais invasivos.

O tratamento preconizado é a IgIV ou a plasmaferese, sendo a primeira mais utilizada devido a sua conveniência e disponibilidade. A paciente relatada foi submetida a tratamento com IgIV $2 \mathrm{~g} / \mathrm{kg}$ por cinco dias e apresentou melhora após o terceiro dia do tratamento. A fisioterapia motora, também indicada em todos os casos de SGB conforme a literatura, foi indicada para a paciente.

Para concluir, apesar de a SGB não ser tão comum na infância, deve ser lembrada e investigada em todos os pacientes com paralisia flácida. É uma doença com evolução benigna, mas pode apresentar-se de forma grave com sequelas permanentes e incapacitantes, e que pode levar o paciente a óbito por complicações totalmente preveníveis. 0 tratamento independe da gravidade e deve ser iniciado o mais breve possível, após o início dos sintomas. Na faixa etária pediátrica, tem bom prognóstico na maioria dos casos, com retorno a todas as atividades em até dois anos. A paciente relatada evoluiu de forma bem favorável, recuperando todas as atividades em um mês após o término do tratamento e sem uso de medicação para controle da dor.

\section{REFERÊNCIAS}

1. João PRD. Síndrome de Guillain-Barré. In: Associação de Medicina Intensiva Brasileira, Sociedade Brasileira de Pediatria; Piva JP, Carvalho WB, organizadores. PROTIPED Programa de Atualização em Terapia Intensiva Pediátrica: Ciclo 6. Porto Alegre: Artmed Panamericana; 2014. p. 1001-128. (Sistema de Educação Continuada a Distância, v.1).

2. Erazo Torricelli R. Sindrome de Guillain Barre en pediatria. Medicina (Buenos Aires) 2009;69 (1 Suppl 1):84-91.

3. McGrogan A, Madle GC, Seaman HE, de Vries CS. The epidemiology of Guillain-Barré syndrome worldwide. Neuroepidemiology. 2009;32(2):150-63.

4. Lee JH, Sung IY, Rew IS. Clinical presentation and prognosis of childhood Guillain-Barré syndrome. J Paediatr Child Health. 2008 Jul-Aug;44(7-8):449-54.

5. Schestatsky P. Definição, diagnóstico e tratamento da dor neuropática. Rev HCPA 2008;28(3):177-87.

6. Poropatich KO, Walker CL, Black RE. Quantifying the association between Campylobacter infection and Guillain-Barré syndrome: a systematic review. J Health Popul Nutr. 2010 Dec;28(6):545-52.

7. Schleicher GK, Black A, Mochan A, Richards GA. Effect of human immunodeficiency vírus on intensive care outcome of patients with Guillain-Barré syndrome. Crit Care Med. 2003 Jun;31(6):1848-50.

8. Gonçalves E. Acute inflammatory demyelinating polyradiculoneuropathy (Guillain-Barré syndrome) 
following dengue fever. Rev Inst Med Trop Sao Paulo. 2011 Jul-Aug;53(4):223-5.

9. Li S, Yu M, Li H, Zhang H, Jiang Y. IL-17 and IL-22 in cerebroespinal fluid and plasma are elevated in Guillain-Barré syndrome. Mediators inflamm. 2012;2012:260473.

10. Schleicher GK, Black A, Mochan A, Richards GA. Effect of human immunodeficiency virus on intensive outcome of patients with Guillain-Barré syndrome. Crit Care Med. 2003 Jun;31 (6):1848-50. 